\title{
Muslim American physicians' views on brain death: Findings from a national survey
}

\author{
Sadaf Popal, Stephen Hall' ${ }^{1}$, Aasim I. Padela ${ }^{1,2}$ \\ Touro College of Osteopathic Medicine, New York, ${ }^{1}$ Initiative on Islam and Medicine, ${ }^{2}$ Section of Emergency Medicine, The University of \\ Chicago, Chicago, IL, USA
}

\begin{tabular}{|c|}
\hline Access this article online \\
\hline Website: www.avicennajmed.com \\
\hline DOI: 10.4103/ajm.ajm_51_20 \\
\hline Quick Response Code: \\
\hline \\
\hline \\
\hline
\end{tabular}

\begin{abstract}
Background: Biotechnology has introduced a new physiological state, "brain death," that continues to attract controversy and confusion. While variability in diagnostic criteria for, and physician practices regarding, "brain death" has been studied, few studies examine physicians' normative views on the significance of "brain death" and how religiosity implicates these views. Objective: The objective is to assess how Muslim physicians' views on death, and how their religiosity and acculturation, associate with their perceptions of "brain death." Methods: A randomized national sample of 626 American Muslim physicians completed a mailed questionnaire assessing sociodemographic characteristics, religiosity, and views about death. Measures of religious practice and acculturation were analyzed as predictors of physician views at the bivariate and multivariable levels. In conducting the multivariate analysis, $P$-values less than 0.05 were deemed statistically significant. Results: Two-hundred and fifty-five respondents completed the survey ( $41 \%$ response rate). Most participants agreed that death is the irreversible cessation of cardiac and respiratory function (90\%), while half agreed or disagreed with other definitions of death, such as loss of personhood or the equivalence of cardiopulmonary and neurological criteria for death. Physicians who scored higher on the religious practice scale had significantly lower odds of agreeing with the statement; "brain death" signifies the departure of the soul from the body [odds ratio $(\mathrm{OR})=0.57,95 \%$ confidence interval $(\mathrm{Cl}): 0.33-0.98$ ] Those who were born in the US, or immigrated to the US as a child, had greater odds of viewing death as the irreversible loss of personhood and consciousness [OR $=3.52,95 \% \mathrm{Cl}$ : 1.62-7.63]. Conclusion: Physician characteristics such as religiosity and acculturation appear to influence their views on what constitutes death and how it should be diagnosed. In our sample of Muslim physicians, there appears to be significant reservation toward equating neurological and cardiopulmonary criteria to determine death and disquiet regarding the meaning of "brain death" in general.
\end{abstract}

Key words: Doctors, end-of-life, ethics, Islam, personhood

\section{INTRODUCTION}

Biotechnology has obscured the traditional markers of death and challenged societies to consider anew how to link legal, clinical, and communal perspectives on what signifies death. Certainly, advances in medicine have introduced a new physiology, the "brain dead" state, that confounds patients, families, and even some clinicians, even though it represents a legal definition for death within the US and is largely accepted as a clinical standard for death globally.

Address for correspondence: Mr Sadaf Popal.

Touro College of Osteopathic Medicine, New York, NY 10027, USA

E-mail: spopal3@student.touro.edu
This confusion is somewhat linked to the fact that there is variability in the criteria for assessing the neurological standards for death. ${ }^{[1-4]}$ Furthermore in the US, the states of New York and New Jersey allow religious exemptions

This is an open access journal, and articles are distributed under the terms of the Creative Commons Attribution-NonCommercial-ShareAlike 4.0 License, which allows others to remix, tweak, and build upon the work non-commercially, as long as appropriate credit is given and the new creations are licensed under the identical terms.

For reprints contact: reprints@medknow.com

Cite this article as: Popal S, Hall S, Padela Al. Muslim American physicians' views on brain death: Findings from a national survey. Avicenna $\mathrm{J}$ Med 2021;11:63-9. 
to being classified as dead once "brain death" has been diagnosed. ${ }^{[5]}$ Thus, one can be "dead" in one locality but not in another. Moving beyond the legal, some religious communities remain unconvinced that "brain death" accords with their religious ontology of a dead state, thus further complicating communication and decision-making in hospitals around termination of life support. ${ }^{[6]}$

Hence, the definition of death should not be reduced to a clinical diagnosis without considering the legal, philosophical, and religious questions that arise. Since physicians serve as decision-makers and advisors in clinical care, it is vital to understand how physicians' values are challenged by "brain death." Accordingly, studies done in both Poland and Germany have linked lower organ procurement rates to physicians' hesitancy in declaring a patient as brain dead even when clear clinical signs were present. ${ }^{[7,8]}$ One study done in Saudi Arabia among Arab Muslim physicians found that it was permissible to execute any necessary intervention in the event of cardiac arrest for $5 \%$ of the "brain dead" patients. ${ }^{[9]}$ More significantly, a study in Turkey found that $38.2 \%$ of the Muslim physicians felt that patients who were diagnosed as "brain dead" should be kept alive for as long as possible. ${ }^{[10]}$

While some of this evidenced hesitation to declare "brain death" may be based in scientific and physiologic ambiguities, a physician's beliefs, culture, and religion may indeed play a role in their decision-making. Certainly, research documents how physicians' recommendations are influenced by cultural, personal, religious, and sociological factors. ${ }^{[1-15]}$ Hence, some physicians might not equate a "brain dead" individual as death of the person due to their personal, cultural, or religious beliefs and thus recommend continuing life-sustaining therapies or "full-code" status. Identifying which factors and how far these ideas impact physicians' perceptions and recommendations regarding life support are important to understanding end-of-life healthcare delivery.

For example, although it has been recorded that some Muslim patients reject "brain death" diagnosis as true death ${ }^{[16]}$ less studied are Muslim physicians' perceptions of "brain death" and the influence of physician religiosity upon these understandings. Shaykh Tantawi, a former grand mufti of Egypt, accords physicians a prominent role in determining death as he holds that physicians, and not religious scholars, as the ones who can accurately surmise whether life has left the body. ${ }^{[17]}$ Accordingly, Muslim physicians' perceptions of "brain death" may implicate their recommendations to patients and families regarding organ procurement and withdrawal of ineffective medical therapy. Scant research foreshadows such as US Muslim physicians have higher odds of objecting to physicianassisted suicide, terminal sedation, and withdrawal of life support. ${ }^{[18]}$

This study assesses how Muslim physicians understand "brain death" and how their religiosity and other characteristics associate with these views. We hypothesize that religious physicians do not equate "brain death" diagnosis with death because some religious edicts do not consider "brain death" to represent the ontological death of the human being. Furthermore, since the medical convention has narrowed the death concept to a physiological diagnosis, we hypothesize that American Muslim physicians who have extended training in the US would perceive "brain death" as a loss of personhood and consciousness.

\section{METHODS}

Survey instrument development, participant recruitment, and data collection

Study methods have been described in detail elsewhere and will be summarized here. ${ }^{[19]}$ The questionnaire included existing instruments as well as items developed de novo and was refined iteratively through expert panel review. The expert panel consisted of senior researchers with expertise in national physician surveys regarding religiosity and bioethical attitudes as well as prominent Muslim physician leaders known to the research team. After refining items for clarity and reducing redundant items, a pilot version of the survey was field-tested through cognitive interviews and time trials with a group of physician-researchers at a research workshop. The final survey comprised of 56 questions and we utilized the Tailored Design Method strategies in the outlay of the final questionnaire. ${ }^{[20]}$ The study population derived from the membership roster of the Islamic Medical Association of North America (IMANA) in 2013 containing 1972 unique members with mailing addresses. From this list, 746 randomly selected members were mailed an introductory letter regarding survey participation. After this mailing, members with undeliverable addresses $(n=100)$, those who were not practicing physicians $(n=16)$, those deceased $(n=2)$, as well as those no longer living within the US $(n=1)$ or not selfidentifying as Muslim $(n=1)$, were excluded yielding 626 potential respondents. We sent the survey to all 626 potential respondents by post-mail in three waves. Using Dilman's methodology, we incentivized participation with a two-dollar bill enclosed in the first questionnaire and followed up with a reminder postcard 10 days later. Five weeks after the reminder postcard, we sent an additional copy of the questionnaire to all non-respondents, with a third copy of the questionnaire following five weeks after the second. The third questionnaire included the guarantee of a book on Islam and medicine as 
an additional incentive. We mailed a final postcard reminder before the end of the data collection period, which included a web address to access an online version of the questionnaire. To further encourage participation, periodic email reminders were sent through the IMANA listserv, and the final email before survey closing noted that all respondents would be entered into an iPad raffle.

The project was approved by the Institutional Review Board of the Biological Sciences Division at the University of Chicago.

\section{Variables of interest}

\section{Outcome domains}

Items relevant for this paper assessed physician views on various definitions of death: (i) "I consider death to be the irreversible cessation of cardiac and respiratory function," (ii) "I consider death to be the irreversible loss of 'personhood' and 'consciousness," (iii) "'brain death' and cardiac death are the same state (i.e., both signifying a dead individual)," and (iv) "brain death' signifies the departure of a person's soul from the body." These outcomes were based on other national physician surveys ${ }^{[21]}$ and physicians were asked to rate the extent to which they agree or disagree with each statement along a four-point Likert-type agreement scale.

\section{Predictor domains}

These were (i) participant religiosity and (ii) acculturation. Participant religiosity was assessed using five items. Three items, borrowed from the Duke University Religion Index (DUREL), examined organizational and non-organizational religious activity by assessing the frequency with which participants attended congregational worship, performed Islamic ritual prayers, and read the Qur'an. ${ }^{[22]}$ Another item, borrowed from a national study among US physicians, ${ }^{[23]}$ inquired about participation in Ramadan fasting. Lastly, an item was constructed to assess adherence to religious guidelines regarding meat consumption. Each response category within the five items was ordered from "low" to "high" religiosity and assigned a value according to the number of response categories in the item. These five items were summed into a single measure to quantify "religiosity," with higher scores denoting higher degrees of religious practice.

Alongside physician religiosity, we measured physician acculturation using an item assessing their familial migration history. Participants were asked to select whether they (i) were born in the US, (ii) immigrated to the US as a child, (iii) immigrated to the US as an adult, or (iv) both of their parents were born in the US.

Additionally, age, sex, community setting, race/ethnicity, years of medical practice, intrinsic religiosity, and the percent of the respondent's patient population that is Muslim were collected as potential predictor variables.

\section{Statistical analyses}

For ease of interpretation, response categories that contained less than $5 \%$ of the total observations were collapsed into an adjacent category. In addition, the religious practices variables were combined into a single measure of religious practice, with larger scores denoting higher degrees of practice. Complete case analysis was used to generate final models. All analyses were performed with STATA/MP version 15 statistical software (StataCorp LLC, College Station, TX, USA).

Associations between predictor and outcome domains were assessed at the bivariate and multivariable levels, using $\chi^{2}$, $t$-tests, and logistic regression modeling. Percentages were used to describe categorical data and means for continuous data. Given the exploratory nature of the study, model building utilized a forward selection method. Using the predictor domains outlined earlier, and based on hypotheses of associations between potential predictors and our outcomes, each predictor was entered sequentially into an ordered logistic regression model and multicollinearity was assessed when there was more than one significant predictor $(P \leq 0.10)$. When it appeared that two items within a domain were collinear, the Akaike information criterion (AIC) was used to select the item with the more significant relationship, and that item was carried forth into the final model as a predictor variable. Regression coefficients were converted to odds ratios, and $P$-values less than 0.05 were deemed statistically significant.

\section{RESULTS}

Sociodemographic and religious profile of participants

A total of 255 participants completed the survey (response rate of $41 \%)$. The mean age was 52 years, most respondents were male (70\%), South Asian (70\%), of Sunni affiliation (91\%), and had practiced medicine in the US for greater than 10 years (72\%). Most (89\%) also reported that religion was either a very important or the most important part of their life. The majority reported attending congregational worship services at least once a month (77\%), praying five times a day (63\%), and fasting Ramadan strictly (85\%). Participants had a mean religiosity score of 2.4 (range: $1-3.3$ ) [Tables 1 and 2].

\section{Perceptions of death}

The overwhelming majority of participants agreed that death is the irreversible cessation of cardiac and respiratory 


\begin{tabular}{lc}
\hline Table I: Sociodemographic characteristics, $\mathbf{N}=\mathbf{2 5 5}$ \\
\hline Characteristic & $\boldsymbol{n}(\%)$, \\
& $\boldsymbol{n}=\mathbf{2 5 5}$ \\
\hline Sex, $n=246$ & \\
Female & $74(30.1)$ \\
Male & $172(69.9)$ \\
Race/ethnicity, $n=247$ & \\
Black/African American & $2(0.8)$ \\
East Asian/Pacific Islander & $2(0.8)$ \\
South Asian & $172(69.6)$ \\
White or Caucasian & $10(4.1)$ \\
Arab/Middle Eastern & $54(21.9)$ \\
Other & $7(2.8)$ \\
Religious affiliation with Islam, $n=244$ & \\
Sunni & $222(91.0)$ \\
Shiite & $11(4.5)$ \\
Unknown & $11(4.5)$ \\
Length of time in the US, $n=247$ & \\
Born in the US & $47(19.0)$ \\
Immigrated as a child & $39(15.8)$ \\
Immigrated as an adult & $158(64.0)$ \\
Both parents born in the US & $3(1.2)$ \\
Medical specialty, $n=24 I$ & \\
Primary care specialties & $72(29.6)$ \\
Internal medicine subspecialties & $43(17.8)$ \\
Pediatric subspecialties & $9(3.8)$ \\
General surgery & $10(4.2)$ \\
Surgical subspecialties & $30(12.5)$ \\
Psychiatry & $13(5.4)$ \\
Obstetrics/gynecology & $13(5.4)$ \\
Other & $51(21.2)$ \\
Mean \pm standard deviation & \\
Age, $n=238$ & $52.1 \pm 15.8$ \\
Years of medical practice, $n=239$ & $23.9 \pm 15.4$ \\
\hline & \\
&
\end{tabular}

function (90\%), yet participants were divided on whether "brain death" and cardiac death are equivalent states (54\% agreed). Approximately half considered death to be the irreversible loss of "personhood" and "consciousness" (42\%) and "brain death" to signify the departure of one's soul from the body (50\%). In the bivariate analysis, years of medical practice was associated with both considering death to be the irreversible cessation of cardiac and respiratory function and the irreversible loss of personhood and consciousness. Additionally, acculturation, proxied by length of time in the US, and age were both associated with views on personhood and consciousness, whereas religiosity was significantly associated with viewing brain death and cardiac death as the same state, and for brain death signifying the departure of a person's soul from the body [Tables 3 and 4].

Univariate analysis greatly reduced the number of variables that were included in our final models. The final models, described in Table 5, were constructed of any variable that was associated with the outcome at $P<0.10$ at the univariate level. Only Model 3 met the criteria for multivariable analysis. In the final analysis, participants who either immigrated to the US as a child or who were born in the US had significantly increased odds of agreeing with the

\begin{tabular}{|c|c|}
\hline Characteristic & $n(\%)$ \\
\hline \multicolumn{2}{|c|}{$\begin{array}{l}\text { Frequency of attendance at congregational services, } \\
n=25 \mathrm{I}\end{array}$} \\
\hline More than once a year & $59(23.5)$ \\
\hline More than once a month & $128(5 \mid .0)$ \\
\hline Several times a week/daily & $64(25.5)$ \\
\hline \multicolumn{2}{|l|}{ Frequency of prayer, $n=25 \mathrm{I}$} \\
\hline Never/at least once a week & $28(11.2)$ \\
\hline At least once a day & $65(25.9)$ \\
\hline Five times a day & $158(62.9)$ \\
\hline \multicolumn{2}{|c|}{ Frequency of reading the Qur'an, $n=25 \mathrm{I}$} \\
\hline Never/on special occasion & $90(35.9)$ \\
\hline Weekly or less & $82(32.7)$ \\
\hline Daily & $79(31.5)$ \\
\hline \multicolumn{2}{|c|}{ Extent at which keep Ramadan fast, $n=253$} \\
\hline Not to somewhat & $38(15.0)$ \\
\hline Strictly & $215(85.0)$ \\
\hline \multicolumn{2}{|l|}{ Religious importance, $n=25 \mathrm{I}$} \\
\hline Most important part of life & $136(54.2)$ \\
\hline Very fairly important & II5 (45.8) \\
\hline \multicolumn{2}{|l|}{ Food habits, $n=248$} \\
\hline Most religious & $64(25.8)$ \\
\hline Very religious & $74(29.8)$ \\
\hline Fairly religious & $96(38.7)$ \\
\hline Not religious & $14(5.6)$ \\
\hline \multicolumn{2}{|l|}{ Mean \pm standard deviation, range } \\
\hline Religiosity, $n=248$ & $2.4 \pm 0.5, \mathrm{l}-3.3$ \\
\hline
\end{tabular}

statement "I consider death to be the irreversible loss of 'personhood' and 'consciousness"' when compared with those who immigrated to the US as an adult [odds ratio $(\mathrm{OR})=3.52$, 95\% confidence interval (CI): 1.62-7.63]. Whereas those who scored higher on the religious practice scale (denoting a higher degree of religious practice) had significantly lower odds of agreeing with the statement "brain death" signifies the departure of a person's soul from the body" when compared with those with lower scores [OR $=0.57,95 \%$ CI: 0.33-0.98]. Similarly, scoring higher on the religious practice scale was marginally associated with greater odds of disagreeing with the statement "brain death" and cardiac death are the same state (i.e., both signifying a dead individual)" [OR $=0.59,95 \%$ CI: 0.34-1.01]. A trend was also observed for the statement "I consider death to be the irreversible cessation of cardiac and respiratory function," with those who reported more years of medical practice demonstrating lower odds of agreement $[\mathrm{OR}=0.59$, 95\% CI: 0.33-1.04] [Table 5].

\section{DISCUSSION}

In summary, we found that Muslim physicians have reservations about the significance of "brain death" and that religiosity and duration of residence in the US are associated with their views on what signifies the death of the individual. As illustrated in Table 3, an overwhelming majority agreed with the cardiopulmonary criteria for death, but almost half did not agree that "brain death" 
and cardiopulmonary cessation are equivalent markers of death. Our findings from Tables 4 and 5 further suggest that Muslim physicians with greater levels of religious practice are less likely to believe "brain death" and cardiopulmonary criteria can be equated and that "brain death" represents death according to Islam. Additionally, as depicted in Table 5, we found that Muslim physicians who resided in the US for a longer period had higher odds of considering "brain death" to be a loss of personhood and consciousness. In what follows we comment on the significance of several of these findings.
Our finding that most physicians view cessation of cardiopulmonary function to signify death is not surprising; this notion is considered the traditional and timeless standard for death determination. It remains a legal standard for death in the US through The Uniform Death Declaration Act (UDDA) and is recognized by Islamic scholars as a marker of death. ${ }^{[21]}$ The fact that more than half of the Muslim physicians were divided in equating "brain death" with cardiopulmonary death resonates with a survey of American neurologists, whereas more than half of the neurologists did not equate "brain death" to cardiac death. ${ }^{[24]}$

\begin{tabular}{|c|c|c|c|c|}
\hline Statement & $\begin{array}{l}\text { Strongly disagree, } \\
n(\%)\end{array}$ & Disagree, $n(\%)$ & Agree, n (\%) & $\begin{array}{c}\text { Strongly } \\
\text { agree, } n \\
(\%)\end{array}$ \\
\hline $\begin{array}{l}\text { I consider death to be the irreversible cessation of cardiac and } \\
\text { respiratory function, } n=250\end{array}$ & $6(2.4)$ & $20(8.0)$ & II (46.8) & $107(42.8)$ \\
\hline $\begin{array}{l}\text { I consider death to be the irreversible loss of "personhood" and } \\
\text { "consciousness," } n=245\end{array}$ & 31 (I2.7) & 110 (44.9) & $75(30.6)$ & $29(11.8)$ \\
\hline $\begin{array}{l}\text { Brain death and cardiac death are the same state (i.e., both signifying } \\
\text { a dead individual), } n=246\end{array}$ & $27(11.0)$ & $87(35.4)$ & $86(35.0)$ & $46(18.7)$ \\
\hline $\begin{array}{l}\text { Brain death signifies the departure of a person's soul from the body, } \\
n=243\end{array}$ & $26(10.7)$ & $96(39.5)$ & $87(35.8)$ & $34(14.0)$ \\
\hline
\end{tabular}

\begin{tabular}{|c|c|c|c|c|}
\hline \multirow[t]{2}{*}{ Predictor } & $\begin{array}{l}\text { I consider death to be the } \\
\text { irreversible cessation of } \\
\text { cardiac and respiratory } \\
\text { function }\end{array}$ & $\begin{array}{l}\text { I consider death to be } \\
\text { the irreversible loss } \\
\text { of "personhood" and } \\
\text { "consciousness" }\end{array}$ & $\begin{array}{l}\text { Brain death and cardiac death are } \\
\text { the same state (i.e., both signifying a } \\
\text { dead individual) }\end{array}$ & $\begin{array}{c}\text { Brain death signifies } \\
\text { the departure of a } \\
\text { person's soul from } \\
\text { the body }\end{array}$ \\
\hline & \multicolumn{4}{|c|}{$P$-value } \\
\hline Sex' & 0.415 & 0.353 & 0.413 & 0.124 \\
\hline Race/ethnicity' & 0.669 & 0.852 & 0.933 & 0.248 \\
\hline Length of time in the US' & 0.379 & $<0.001$ & 0.248 & 0.482 \\
\hline $\mathrm{Age}^{2}$ & 0.161 & $<0.001$ & 0.387 & 0.712 \\
\hline Years of medical practice ${ }^{2}$ & 0.070 & $<0.001$ & 0.334 & 0.863 \\
\hline Religiosity ${ }^{2}$ & 0.248 & 0.434 & 0.055 & 0.043 \\
\hline Religious importance' & 1.000 & 0.410 & 0.696 & 0.692 \\
\hline \multicolumn{5}{|l|}{ Community setting' } \\
\hline Urban & REF & REF & REF & REF \\
\hline Suburban & 0.123 & 0.194 & 0.722 & 0.734 \\
\hline Rural & 0.626 & 0.950 & 0.383 & 0.416 \\
\hline
\end{tabular}

\begin{tabular}{|c|c|c|}
\hline Model & Odds ratio ( $95 \%$ confidence interval) & $P$-value \\
\hline \multicolumn{3}{|c|}{$\begin{array}{l}\text { Model I (bivariate): I consider death to be the irreversible cessation of cardiac and } \\
\text { respiratory function, } n=235\end{array}$} \\
\hline Years of medical practice & $0.59(0.33-1.04)$ & 0.07 \\
\hline \multicolumn{3}{|c|}{$\begin{array}{l}\text { Model } 2 \text { (multivariate): I consider death to be the irreversible loss of "personhood" } \\
\text { and "consciousness," } n=229\end{array}$} \\
\hline Duration in the US* & $3.52(1.62,7.63)$ & 0.001 \\
\hline Years of medical practice & $0.75(0.47-1.20)$ & 0.232 \\
\hline \multicolumn{3}{|c|}{$\begin{array}{l}\text { Model } 3 \text { (bivariate): Brain death and cardiac death are the same state (i.e., both } \\
\text { signifying a dead individual), } n=246\end{array}$} \\
\hline Religiosity & $0.59(0.34-1.01)$ & 0.055 \\
\hline \multicolumn{3}{|c|}{$\begin{array}{l}\text { Model } 4 \text { (bivariate): Brain death signifies the departure of a person's soul from the } \\
\text { body, } n=243\end{array}$} \\
\hline Religiosity & $0.57(0.33-0.98)$ & 0.043 \\
\hline
\end{tabular}


Our finding that physicians with higher religiosity had lower odds of equating neurological criteria and cardiopulmonary criteria for assessing death and that they also had lower odds of considering "brain death" to signify departure of the soul points toward religious disquiet over this construction of death. There indeed are two morally equivalent views on whether "brain death" signifies legal death according to Islamic jurists, and religious physicians may simply be reflecting their preference for the view that considers "brain death" to be a dying, but not dead, state. ${ }^{[21,23,25,26]}$ Although one cannot assume that physicians are well-read in Islamic juridical outputs, common religious resources may throw "brain death" into uncertainty. For example, the Qur'an defines death as the departure of the soul from the body but does not identify the location of the soul nor do statements from the Prophet Muhammad clarify whether brain functions are related to the soul. As such uncertainty exists within the religious sources and may be reflected in clinical beliefs. Rather, some Muslim scholars have contended that the beating heart is connected to the soul, ${ }^{[27]}$ implying that death occurs during cardiac death and not during "brain death."

Our finding that physicians with greater years of residency in the US had higher odds of considering "brain death" to signify loss of consciousness and personhood agrees with data from a survey of American neurologists which found that the most common justification for "brain death" to be death is that it represents an irreversible loss of consciousness and personhood. ${ }^{[16]}$ This notion is cited in much literature which claims that what differentiates a human from other animals is their ability to have cognition. ${ }^{[22,28]}$ Once cognitive ability is lost, the death of an individual has occurred. ${ }^{[22,28]}$ Yet, the US shies away from applying the higher "brain death" criteria which encompasses cognition due to inadequate testing of higher cortical function. ${ }^{[29]}$ The UDDA applies the "whole brain criteria" for neurological determination of death precisely because such a definition is considered acceptable in lieu of higher "brain death" loss. ${ }^{[22,28]}$ Critics note that equating "brain death" with death because of loss of consciousness would imply that those in a persistent vegetative state and anencephaly are also dead, an implication that society may not be ready to accept. ${ }^{[7]}$ Despite this criticism and uncertainty in testing higher cortical function, Muslim physicians with a longer duration in the US are more likely to equate "brain death" to loss of personhood and consciousness. This finding is interesting because the loss of personhood and consciousness cannot be verified at the bedside with certainty, and according to some certainty is religiously required when evaluating death. ${ }^{[30]}$
The variability in diagnosing "brain death" has urged many researchers and physicians to call for implementation of more specific neurologic criteria; however, research lacks in addressing the moral and ethical challenges, physicians' attitudes, and beliefs introduced in determining "brain death." ${ }^{[3]}$ Moreover, the impact of such views on patient/ family discussions and patient outcomes deserves greater study. While our study suggests that Muslim physicians may have hesitation about declaring individuals dead by neurological criteria, it is not known whether these views impact actual practice regarding organ retrieval, death declaration, and withdrawal of life support and is a limitation of our study. Moreover, while some Islamic views may give pause to "brain death," other cultures may find "brain death" fully acceptable. For example, a survey of Chinese medical providers found that the belief that the soul resides in the brain was one of the most integral determinants of upholding the "brain death" diagnosis. ${ }^{[31]}$ Additionally, given the increasing political maneuvering toward conscience rights, it would be worth examining whether some physicians claim conscience regarding determination of death by neurological criteria. Moreover, ethicists have called for informed consent procedures be used with families when deciding to declare death by neurological criteria. ${ }^{[32]} \mathrm{We}$ hope that our study further demonstrates the importance of acknowledging how physicians' sociological and religious values mold their perceptions of "brain death" and sets up research on how these perceptions impact clinical decisionmaking at the bedside.

The results of this study should be interpreted in light of several limitations. While using the IMANA membership roster allowed for the generation of a national sample of Muslim physicians, it also introduced selection bias toward a respondent pool that has a more prominent religious identity and practice. Relatedly, non-respondents may have differed from respondents; hence, our findings should not be generalized to all Muslim American physicians without caution. Further, while physician choice of specialty may influence perceptions of brain death, we were not powered to account for specialty effect in our analysis. In addition, our composite religious practice variable has not yet been validated, nor its psychometric properties tested, across multiple samples. Yet, combining religiosity items into a single variable has precedent. ${ }^{[33]}$ Additionally, the Cronbach's a for the scale in our sample was 0.7 , suggesting sufficient internal consistency reliability for use as a single scale. ${ }^{[34]}$

In this study, we found that Muslim physicians' religious and demographic characteristics associate with their perceptions of "brain death." Greater research is needed to evaluate how such perceptions impact physician recommendations 
and practice regarding organ retrieval, death declaration, and withdrawal of life support. Furthermore, given that the normative implications of "brain death" continue to challenge some physician groups, policy action regarding standardizing communication with families, and offering physicians recourse to conscience clauses, may improve clinical practice.

\section{Financial support and sponsorship}

Nil.

\section{Conflicts of interest}

There are no conflicts of interest.

\section{References}

1. Braksick SA, Robinson CP, Gronseth GS, Hocker S, Wijdicks EFM, Rabinstein AA. Variability in reported physician practices for brain death determination. Neurology 2019;92:e888-94.

2. Goila AK, Pawar M. The diagnosis of brain death. Indian J Crit Care Med 2009;13:7-11.

3. Pandey A, Sahota P, Nattanmai P, Newey CR. Variability in diagnosing brain death at an Academic Medical Center. Neurosci J 2017;2017:6017958.

4. Wijdicks EF. Brain death worldwide: Accepted fact but no global consensus in diagnostic criteria. Neurology 2002;58:20-5.

5. Olick RS. Brain death, religious freedom, and public policy: New Jersey's landmark legislative initiative. Kennedy Inst Ethics J 1991;1:275-92.

6. Grodin MA. Religious exemptions: Brain death and Jewish law.J Church State 1994;36:357-72.

7. Kosieradzki M, Jakubowska-Winecka A, Feliksiak M, Kawalec I, Zawilinska E, Danielewicz R, et al. Attitude of healthcare professionals: A major limiting factor in organ donation from brain-dead donors. J Transplant 2014;2014:296912.

8. Yılmaz Ferhatoglu S, Yapici N. Brain death and organ donation rates in a city hospital: A retrospective study. Cureus 2019;11:e4006.

9. Khalid I, Hamad WJ, Khalid TJ, Kadri M, Qushmaq I. End-of-life care in Muslim brain-dead patients: A 10-year experience. Am J Hosp Palliat Care 2013;30:413-8.

10. Hot I, Vatanoğlu E, Dirican A, Dogan H. Attitudes toward death and brain death among Turkey's physicians: A brief research report. Omega (Westport) 2009;59:339-49.

11. Chung GS, Yoon JD, Rasinski KA, Curlin FA. US physicians' opinions about distinctions between withdrawing and withholding lifesustaining treatment. J Relig Health 2016;55:1596-606.

12. Wenger NS, Carmel S. Physicians' religiosity and end-of-life care attitudes and behaviors. Mt Sinai J Med 2004;71:335-43.

13. Koenig HG, Hooten EG, Lindsay-Calkins E, Meador KG. Spirituality in medical school curricula: Findings from a national survey. Int J Psychiatry Med 2010;40:391-8.

14. Balboni TA, Balboni M, Enzinger AC, Gallivan K, Paulk ME, Wright A, et al. Provision of spiritual support to patients with advanced cancer by religious communities and associations with medical care at the end of life. JAMA Intern Med 2013;173:1109-17.

15. MacLean CD, Susi B, Phifer N, Schultz L, Bynum D, Franco M, et al. Patient preference for physician discussion and practice of spirituality. J Gen Intern Med 2003;18:38-43.

16. Berner D, Gaeta S. Religion based non-acceptance of brain death, an end-of-life ethical dilemma. Crit Care Med 2012;40:1-328.

17. Brockopp JE. Islamic Ethics of Life: Abortion, War, and Euthanasia. Columbia, SC: University of South Carolina Press; 2003. p. 177.

18. Rady MY, Verheijde JL. A response to the legitimacy of brain death in Islam. J Relig Health 2016;55:1198-205.

19. Padela AI, Adam H, Ahmad M, Hosseinian Z, Curlin F. Religious identity and workplace discrimination: A national survey of American Muslim physicians. AJOB Empirical Bioethics 2016;7:149-59.

20. Dillman DA. Mail and Internet Surveys: The Tailored Design Method. 2nd ed. New York: John Wiley \& Sons, Inc.; 2000.

21. Padela AI, Arozullah A, Moosa E. Brain death in Islamic ethico-legal deliberation: Challenges for applied islamic bioethics. Bioethics 2013;27:132-9.

22. Koenig HG, Büssing A. The Duke University Religion Index (DUREL): A fiveitem measure for use in epidemological studies. Religions 2010;1:78-85.

23. Curlin F, Lantos JD, Roach CJ, Sellegren SA, Chin MH. Religious commitments and clinical practices: A National Physician Survey.J Gen Intern Med 2005;20:629-34.

24. Cranford RE, Smith DR. Consciousness: The most critical moral (constitutional) standard for human personhood. Am J Law Med 1987;13:233-48.

25. Padela AI, Basser TA. Brain death: The challenges of translating medical science into Islamic bioethical discourse. Med Law 2012;31:433-50.

26. Padela AI. The perspectives of Islamic jurists on the brain death as legal death in Islam. J Relig Health 2016;55:1215-7.

27. Rady MY, Verheijde JL, Ali MS. Islam and end-of-life practices in organ donation for transplantation: New questions and serious sociocultural consequences. HEC Forum 2009;21:175-205.

28. Sarbey B. Definitions of death: Brain death and what matters in a person. J Law Biosci 2016;3:743-52.

29. Joffe AR, Anton NR, Duff JP, Decaen A. A survey of American neurologists about brain death: Understanding the conceptual basis and diagnostic tests for brain death. Ann Intensive Care 2012;2:4.

30. Qazi F, Ewell JC, Munawar A, Asrar U, Khan N. The degree of certainty in brain death: Probability in clinical and Islamic legal discourse. Theor Med Bioeth 2013;34:117-31.

31. Yang Q, Fan Y, Cheng Q, Li X, Khoshnood K, Miller G. Acceptance in theory but not practice-Chinese Medical Providers' perception of brain death. Neuroethics 2015;8:299-313.

32. Johnson LSM. The case for reasonable accommodation of conscientious objections to declarations of brain death. J Bioeth Inq 2016;13:105-15.

33. Curlin FA, Chin MH, Sellergren SA, Roach CJ, Lantos JD. The association of physicians' religious characteristics with their attitudes and selfreported behaviors regarding religion and spirituality in the clinical encounter. Med Care 2006;44:446-53.

34. Yoon JD, Rasinski KA, Curlin FA. Moral controversy, directive counsel, and the doctor's role: Findings from a national survey of obstetriciangynecologists. Acad Med 2010;85:1475-81. 